\title{
Short Term Effectiveness of Intraatricular Injection of Methylprednisolone Acetate in Subacromial Impingement Syndrome in a tertiary care hospital.
}

\section{M.Amir Sohail, ${ }^{1}$ Nijat Ali, ${ }^{2}$ Zulfiqar Zahoor Ahmad Cheema, ${ }^{3}$ Sohail Razzaq, ${ }^{4}$ Arif Mahmood, Shafqat Wasim ${ }^{6}$}

\begin{abstract}
Objective: To determine mean decrease in VAS pain score of intraarticular injection of methyl prednisolone acetate in patients of subacromial impingement syndrome.

Methods: Its Descriptive Case Series/ Quasi experimental study. Study was conducted in department of Orthopedics Unit- I, Jinnah hospital Lahore. Study completed in Six months i.e. from June 2014 to December 2014.After taking an informed consent, 70 newly diagnosed cases of Subacromial impingement syndrome by history and examination (described by the patient as pain in subacromial space when the humerus was elevated or internally rotated and tested by having the patient place his hand on the unaffected shoulder and gradually forward flexing the shoulder (positive impingement sign)which have not received any kind of treatment were included.

Results: Effectiveness of intraarticular injection of methyl prednisolone acetate was measured on visual analogue scale (VAS) from 0 to 10 by VAS score after 6 weeks. 70 patients with mean age of $36.2 \pm 10.6$ years were included. 61 patients $(75.7 \%)$ were male, 10 patients $(14.3 \%)$ had gout and $20 \%$ were diabetic. Mean pretreatment VAS score was $5.03 \pm 1.58$ while mean post-treatment VAS score was $3.86 \pm 0.839$. Mean reduction was $1.17 \pm 1.57$ ranged from 2 to 6 . There was non-significant association of age and diabetes with mean reduction in VAS score while female gender and gout were significantly and negatively associated with treatment outcome. It is concluded that mean reduction in VAS score after 6 weeks of treatment of subacromial impingement syndrome after intra articular methylprednisolone injection is $1.17 \pm 1.57$ and acceptable.

Conclusion: It is concluded that intraatricular injection of methyl prednisolone injection is efficacious and effective for treatment of Subacromial impingement syndrome in Pakistani population.

Keyword: subacromial impingement syndrome, intra articular methylprednisolone injection, visual analogue scale, effectiveness.
\end{abstract}

\section{Introduction}

$\mathrm{S}$ ubacromial impingement syndrome (SIS) represents a spectrum of pathology ranging from subacromial bursitis to rotator cuff tendinopathy and full-thickness rotator cuff tears. ${ }^{1}$ It accounts for 44-65 $\%$ of all complaints of shoulder pain.2the Causes of

\begin{tabular}{|c|c|}
\hline 1. M.Amir Sohail & 2. $\mathrm{Ni}$ \\
\hline 3. Zulfiqar Zahoor Ahmad Cheema & 4. Sohail Razzaq \\
\hline 5. Arif Mahmood & 6. Shafqat Wasim \\
\hline $1,2,4$ Dep & Но \\
\hline Dep & $\mathrm{G}$ \\
\hline$D$ & \\
\hline
\end{tabular}

Correspondence:
Subacromial impingement syndrome includes anatomical causes which means abnormal contact between coracoacromial arch and the rotator cuff tear ${ }^{3,4}$ Multiple treatment options are there for the treatment of Subacromial impingement syndrome. Thses includes physiotherapy, shock wave therapy, intraarticular injection and Surgery. Some studies show that physiotherapy should be considered as first line management for Subacromial impingement syndrome. ${ }^{5}$ Shock wave therapy alone are in combination with isokinetic exercises is also recommended for treatment of Subacromial impingement syndrome. ${ }^{6}$ Many Surgical procedures including sub acromial decompression using acromioplasty and bursectomy are recommended. ${ }^{7}$ Although some studies show no big difference between the surgical and non-surgical 
treatment $^{8}$. The gold standard for the treatment of Subacromial impingement syndrome is consider to be the intra articular injection of steroid in combination with anti-inflammatory drugs and isokinetic exercises Triamcinolone and methyl prednisolone in addition with local anesthetic have been tried for intra-articular injection9.In one study, fifty patients with SIS were randomized to three treatment groups. All patients received an injection of $10 \mathrm{ml} 0.5 \%$ bupivacaine, in group 1 without corticosteroid, in group 2 with crystalline corticosteroid and in group 3 with lipoid corticosteroid. Treatment in group 1 had to be stopped because of inefficacy. In groups 2 and 3 favorable results were achieved in 19 out of 40 patients. $^{10}$

McInerney et al, in randomized controlled trial of single subacromial steroid injection in patients of post traumatic persistent rototar cuff impingement studied pain on VAS and shoulder abduction in two groups of patients. group Creceived only local anaesthetic injection and group $\mathrm{S}$ received corticosteroid injection in steroid group mean pain score on VAS was $6 \pm 2$ on start of study and at 6 weeks $70 \%$ patients has pain score at VAS less than 2 . So there was mean difference of 4 on VAS. ${ }^{11}$

JiYeon Hong, in his Comparison of High- and LowDose Corticosteroid in Sub acromial Injection for Periarticular Shoulder Disorder: A Randomized, Triple-Blind, Placebo-Controlled Trial showed a improvement in VAS $(5.5 \pm 1.8$ to $1.9 \pm 2.3)$ mean 3.6 after 4 weeks in group 1 which was injected $40 \mathrm{mg}$ corticosteroids. ${ }^{12}$ Temporal outcomes of 100 consecutive patients treated for SIS were prospectively evaluated. Data was collected at 6 weeks, 3 months, 6 months, 1 year and final follow up at 2 years.In that group, the average decrease in the pain score from 4.8 to 0.6. Improvement in patient VAS pain scores occurred between the initial and 6-week evaluations (4.8 \pm 1.9 to $2.7 \pm 2.1, \mathrm{P}<.0001$ ), between the 6-week and 6-month evaluations ( $2.7 \pm 2.1$ to $2.0 \pm 2.1, \mathrm{P}=.02$ ), and between the 6-month and 1-year evaluations (2.0 \pm 2.1 to $0.9 \pm 1.5, \mathrm{P}=.0002) .{ }^{5}$ Because of difference in mean decrease in VAS in three international studies. Current study aimed to determine short term effectiveness in terms of mean decrease in pain on VAS in Pakistani population regarding intraarticular Injection of Methylprednisolone Acetate in Subacromial Impingement Syndrome.

\section{Methods}

Study was conducted in department of Orthopedics Unit-II, Jinnah hospital Lahore and completed in six months i.e. from June 2014 to December 2014. It was Descriptive Case Series/Quasi experimental study. It was estimated as 70 cases using 95\% confidence level, $\mathrm{d}=0.05$ with an expected mean decrease in VAS after 6 weeks as $2.1 \pm 0.2$ in patients with SIS. Sampling technique was Non-probability consecutive/ purposive sampling. Inclusion criteria include patient from either gender between the age from $21-60$ years, newly diagnose cases of subacromialimpingment by history and examination (a positive impingment sign) as per operational definition who have not receive any kind of treatment. X-ray of the effected shoulder including AP, lateral and exial view are done to rule out other possibilities like fracture around proximal humerus. Exclusion criteria include advanced osteoporosis as diagnosed by $\mathrm{x}$-ray, $\mathrm{H} / \mathrm{O}$ connective tissue disorder, previous $\mathrm{H} / \mathrm{O}$ fracture around shoulder, rheumatoid arthritis and osteoarthritis of shoulder. Patient having previous surgery or intervene impigment syndrome. After an informed consent 70 patients coming to Out Patient Department of Jinnah Hospital Lahore and fulfilling the inclusion criteria were included in the study. Using consecutive non probability sampling, questionnaire containing background information i.e. age, gender and initial pain score on visual analogue scale was recorded. Time of start of symptoms and history of diabetes, gout was recorded as effect modifiers and confounders. Injection of $2 \mathrm{ml}$ methyl prednisolone $(40 \mathrm{mg} / \mathrm{ml})$ along with $8 \mathrm{ml}$ of bupivicain was administered with $21 \mathrm{G}$ needle in orthopedic operation theatre. The included patients were evaluated 6 weeks after intraarticular methylprednisolone injection for pain score on VAS. Data collected was entered and analyzed in the SPSS version 17. Results were projected using descriptive statistics e.g. mean with standard deviation in case of continuous variables like age, pre-treatment and post-treatment VAS, decrease in VAS, frequency and percentages in case of categorical variables like gender. Pretreatment and post treatment VAS score was recorded and mean decrease in VAS was obtained by subtracting post treatment VAS score from pretreatment VAS score. Data was stratified for age, gender, duration of symptoms, diabetes and gout. 


\section{Results}

A visual analogue scale (VAS) is a measurement instrument that tries to measure a characteristic or attitude that is believed to rang across a continuum of values and can not easily be directly be measured ${ }^{13}$. The results derived in this study were based on the patient's own evaluation and assessment of pain 70 individuals were included in our study sample with mean age distribution $36.21 \pm 10.689$ ranging from 21 to 60 years. Mean pretreatment VAS score was $5.03 \pm$ 1.579 ranging from 3 to 9 . Mean post treatment VAS score was $3.86 \pm 0.839$ ranged from 3 to 5 while mean reduction was $1.17 \pm 1.57$ ranged from 2 to 6 (TableI). Study sample $(\mathrm{n}=70)$ consisted of 17 females $(24.3 \%)$ while 53 males $(75.7 \%) 14$ individuals (20\%) among study sample $(n=70)$ were diabetic while remaining 56 (80\%) were non-diabetic. Among study population 10 patients $(14.3 \%)$ had gout. Sample was distributed into two groups, i.e. more (Group I) and less than (Group II) 40 years. Group 1 had 49 individuals $(70 \%)$ while rest of 21 were included in group II (30\%). Mean pretreatment VAS score was $5.03 \pm 1.58$ while mean post-treatment VAS score was $3.86 \pm 0.839 .17$ female patients were having mean decrease in VAS score $0.0588 \pm 1.02899$ while 53 male patients were having $1.5283 \pm 1.55172$ and independent samples $\mathrm{T}$ test showed non-significant results Table-II. Mean reduction in VAS score in 14 diabetic patients was $1.6429 \pm 1.905751$ while in 56 non-diabetics patients Score was $1.0536 \pm$ $1.46994 .^{10}$ patients with gout had mean reduction VAS score $0.1000 \pm 0.99443$ while rest of 60 non-gout patients were having score $1.3500 \pm 1.58194$. Age group 1 had mean reduction in VAS score $1.3878 \pm$ 1.60489 while group II had VAS score $0.6667 \pm$ 1.39044 (Table III).

\section{DISCUSSION}

Table 1: Descriptive Statistics for Age Visual Analogue Scale Score

\begin{tabular}{|c|c|c|c|c|c|}
\hline & $\mathbf{n}$ & Mini & Maxi & Mean & $\begin{array}{c}\text { Std. } \\
\text { Deviation }\end{array}$ \\
\hline Age & 70 & 21 & 60 & 36.21 & 10.689 \\
\hline $\begin{array}{l}\text { Pre Treatment VAS } \\
\text { Score }\end{array}$ & 70 & 3 & 9 & 5.03 & 1.579 \\
\hline $\begin{array}{l}\text { Post Treatment VAS } \\
\text { Score }\end{array}$ & 70 & 3 & 5 & 3.86 & .839 \\
\hline $\begin{array}{l}\text { Difference of VAS } \\
\text { Score }\end{array}$ & 70 & -2.00 & 6.00 & 1.1714 & 1.56938 \\
\hline
\end{tabular}

Table 2: Mean Distribution of Reduction in VAS Score Among Male and Female

\begin{tabular}{ccccc}
\hline & Sex & N & Mean & Std. Deviation \\
\hline Difference in & Female & 17 & .0588 & 1.02899 \\
VAS Score & Male & 53 & 1.5283 & 1.55172 \\
Using Independent Samples t Test, p value $<0.001$ \\
(Highly significant)
\end{tabular}

Table 3: Mean Distribution of Reduction in VAS Score Among in different Age Groups

\begin{tabular}{|ccccc}
\hline & Age Groups & N & Mean & $\begin{array}{c}\text { Std. } \\
\text { Deviation }\end{array}$ \\
\hline Difference & More than 40 years & 49 & 1.3878 & 1.60489 \\
VAS-Score & Less than 40 years & 21 & .6667 & 1.39044 \\
Using Independent Samples t Test, p value $=0.078$ (Non - \\
significant)
\end{tabular}

Subacromial impingement syndrome has been defined by the American Academy of Orthopedic Surgeons as described by the patient as pain in subacromial space when the humerus was elevated or internally rotated and tested by having the patient place his hand on the unaffected shoulder and gradually forward flexing the shoulder (positive impingement sign). The condition is also characterized by severe shoulder pain. Frozen shoulder is a common cause of shoulder disability.

Mean age of 36 years shows that a relatively young population is affected. Involvement of young age patients in this morbidity of reduced activity of shoulder. Subacromial impingement syndrome shows loss of man power and working ability. It also point out to sedentary life style of our young and middle aged population.Pain relief was scored on visual analogue scale from 0 to 10 six weeks after intraarticular injection of methyl prednisolone acetate, effectiveness of intervention was measured by mean reduction in VAS score using paired sample $t$ test. Mean reduction was $1.17 \pm 1.57$ showing effectiveness of our intervention (highly significant $p$ value $<0.001$ ).

Intraarticular steroid injections were found safe in all of our study population. We applied independent sample $t$ test to find whether age is associated with positive outcome or not. We found that it is nonsignificantly associated with treatment outcome. Gender was associated with effectiveness of intraarticular steroid. Male patients had better results as compared to female patients.

Diabetes is on rise in our population as it affected $20 \%$ 
of study population high as compared to reported prevalence of diabetes in other surveys. Diabetes and gout are known to be associated with Subacromial impingement syndrome. In our study gout was associated with effectiveness butdiabetes doesn't affect the outcome of intraarticular steroid in our study population.

\section{Conclusion}

It is concluded that intraatricular injection of methyl prednisolone injection is efficacious and effective for treatment of Subacromial impingement syndrome in Pakistani population. Mean reduction in VAS score after 6 weeks of treatment of subacromial impingement syndrome after intra articular methylprednisolone injection is $1.17 \pm 1.57$ and acceptable. It is hereby recommended that intraarticular steroid injection is advisable in male patients with Subacromial impingement syndrome without concomitant gout.

\section{Author's Contribution}

MAS: StudyDesign, Manuscript writing

NA: Finalization write up collect of results

ZZAC: Literature Search, Write up of Results

SRA: Analysis of results and patient case

AM: Write up of disscussion, table and bars

SW: Overall supervision of Project

\section{References}

1. Harrison AK,Flatow EL. Subacromial Impingement Syndrome; J Am AcadOrthopSurg 2011,:19(11); 701- 708 .

2. Umer M, Qadir I, AzamM.Subacromial impingement syndrome. Orthop Rev (Pavia). 2012,: 9; 4(2).

3. Armstrong J.R: Excission of the acromion in the treatment of supraspinatus syndrome report of 95 excission. J.Bone and joint surgery, 31-B(3):436-442

4. Codman, EA : The shoulder. Rupture of th supraspinatus tendon and other in are about the sub acromial Bursa. Bostan, Thomas Todd,1934

5. 'Physiotherapy' volume 91, issue 3 September 2005 $\mathrm{P}(159-164)$

6. General of orthopedic and sports physical therapy: August 2016 volume 46 issue 9 P(714-725)

7. Campable's operative orthopaedics Frederick M Azar MD, James H Beaty MD, S.Terry Cannal MD 13thEddition implement syndrome. P 2306+-2308

8. Conservative or surgical treatment for sub acromial impingement syndrome: a systemic review. Dorrestijn, M Stevens, JC Winters, K Van der Meer and RL Dierks Center of reviews and dissemination

9. Actaortopedicabrasileira 25(5) July 2017 Vol 25 n.5P(206-208)

10. Plafki C, Steffen R, Willburger RE, Wittenberg RH. Local anaesthetic injection with and without corticosteroids for subacromial impingement syndrome. Intl ortho 2000,24(1); 121-5

11. McInerney, J. J., et al. "Randomised controlled trial of single, subacromial injection of methylprednisolone in patients with persistent, post-traumatic impingment of the shoulder." Emergency medicine journal 20.3 (2003),: 218-221.

12. Cummins CA, Sasso LM, Nicholson D, Impingement syndrome: Temporal outcomes of nonoperative treatment. J Shoulder Elbow Surg 2009, : 18(3)2: 172-177.

13. Journal of clinical nursing $2001 ; 10 \mathrm{P}(697-706)$ 